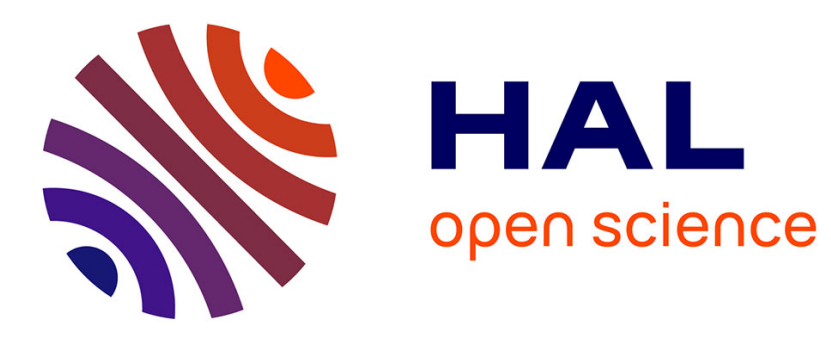

\title{
Porosity measurement by comparison of air volumes
}

\author{
Philippe Leclaire, Olga Umnova, Kirill Horoshenkov, Laurent Maillet
}

\section{To cite this version:}

Philippe Leclaire, Olga Umnova, Kirill Horoshenkov, Laurent Maillet. Porosity measurement by comparison of air volumes. Review of Scientific Instruments, 2003, 74 (3), pp.1366. 10.1063/1.1542666. hal-01326049

\section{HAL Id: hal-01326049 \\ https://hal.science/hal-01326049}

Submitted on 3 Jun 2016

HAL is a multi-disciplinary open access archive for the deposit and dissemination of scientific research documents, whether they are published or not. The documents may come from teaching and research institutions in France or abroad, or from public or private research centers.
L'archive ouverte pluridisciplinaire HAL, est destinée au dépôt et à la diffusion de documents scientifiques de niveau recherche, publiés ou non, émanant des établissements d'enseignement et de recherche français ou étrangers, des laboratoires publics ou privés. 


\title{
Porosity measurement by comparison of air volumes
}

\author{
P. Leclaire ${ }^{\text {a) }}$ and O. Umnova \\ Department of Engineering, University of Hull, Hull HU6 7RX, United Kingdom \\ K. V. Horoshenkov \\ Department of Civil and Environmental Engineering, University of Bradford, Bradford BD7 IDP, \\ United Kingdom \\ L. Maillet \\ Department of Chemistry, University of Hull, Hull HU6 7RX, United Kingdom
}

\begin{abstract}
A method for measuring the volume of a solid with arbitrary shape and the open porosity (volume fraction of the open pores) of air-saturated porous materials is proposed. The experimental principle is inspired from Beranek's method [J. Acoust. Soc. Am. 13, 248 (1942)] based on the application of the ideal gas law to the gas surrounding the solid. The originality of the proposed method lies in the comparison of the volume of a measurement chamber containing the sample with that of an empty reference chamber. During a measurement, the reduction of volume in the measurement chamber due to the introduction of the solid is compensated by increasing the volume of a piston connected to the measurement chamber. An important aspect of this experimental system is that the influence of temperature can be considerably reduced as nearly the same variations of temperature apply simultaneously to the measurement and the reference chambers. A preliminary calibration experiment without sample in the measurement chamber is carried out in order to equalize the volumes of the two chambers. The calibration can be performed once and for all, thus minimizing the number of operations in the measurement process. The porosities of several materials are measured and compared to reference values. The precision and possible future improvements are discussed.
\end{abstract}

\section{INTRODUCTION}

The porosity of a porous material corresponds to the volume proportion of fluid contained in the pores, i.e., the total volume of the fluid in the pores divided by the volume of the sample. It is an essential parameter in the physical and acoustical modeling of porous media. In this article, a method for measuring the porosity of air-saturated materials with reduced thermal effect is proposed. The applications also concern chemistry, the pharmaceutical industry, and powder technology. Determining the porosity is equivalent to measuring the volume of a solid with arbitrary shape. The most common methods involve the saturation of the sample with water. For example, the volume of solid can be measured from the rise of the water level after having plunged the sample in water in a measuring cylinder. Alternatively for a porous solid, the density of the dry sample and the density of the sample when saturated with water provide an evaluation of the porosity. However, water-saturation methods are not always appropriate as these can damage the sample or modify its properties. The description of various methods for measuring porosity such as mercury porosimetry, buoyancy, or methods based on density measurements can be found in Ref. 1. Different types of porosities are defined and open, trapped, or total porosity can be determined depending on the methods selected. The method proposed in this article is based on the compressibility of the air in the connected pores and therefore this method yields the open porosity.

\section{PREVIOUS WORKS}

Beranek $^{2}$ proposed a simple method for the determination of porosity without involving saturation of the sample with water. This method is based on the great difference in compressibility between a solid and a gas. In Beranek's method, a porous sample is introduced in an air-tight chamber that is connected to a U-tube manometer as shown in Fig. 1.

The situation shown in Fig. 1 can be obtained by pouring water from the left branch of the manometer if the U-tube is initially empty. The difference of pressure $(a-b)$ corresponds to the gauge pressure in the chamber. The pressures can be related to volumes with the help of Boyle's law (ideal gas law for a constant temperature process) and if this experiment is done with and then without sample, it is possible to infer the volume proportion of solid and the porosity. Boyle's law assumes that the processes are isothermal. Therefore the experiment must be carried out very slowly and in a thermostatic container, for example, in a tank containing a mixture of liquid water and ice.

Based on this principle, Champoux et al. ${ }^{3}$ designed a much more elaborate system providing results with an excellent precision in a wide range of porosities. Their system involves a micrometer drive for precise variations of volume in the chamber, a sensitive differential pressure transducer to 


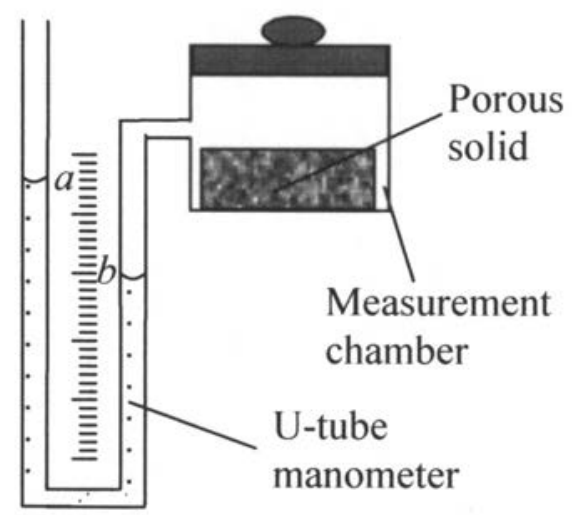

FIG. 1. Experimental setup based on Beranek's method.

replace the U-tube manometer, and a large air reservoir to isolate the apparatus from atmospheric pressure fluctuation. Champoux et al. also gave solutions to achieve a good temperature stabilization.

\section{NEW METHOD BASED ON VOLUME COMPARISON BETWEEN A REFERENCE CHAMBER AND A MEASUREMENT CHAMBER WITH VARIABLE VOLUME}

\section{A. Experimental setup}

The experimental principle of the proposed method is shown in Fig. 2. Two air-tight chambers of approximately 60 $\mathrm{ml}$, a reference and a measurement chamber, are connected to the branches of a U-tube manometer containing water. The volume of the reference chamber must be slightly higher than that of the measurement chamber for a reason that will become apparent later. The manometer is made up of glass tubes with an inner diameter around $5 \mathrm{~mm}$, large enough to neglect capillary effects. Water can be removed from and reinjected in the manometer with the help of a water-drawing piston. If valves $\mathrm{A}$ and $\mathrm{B}$ are closed, drawing water will have the effect of increasing both the reference volume and the volume in which the sample is contained. A measurement

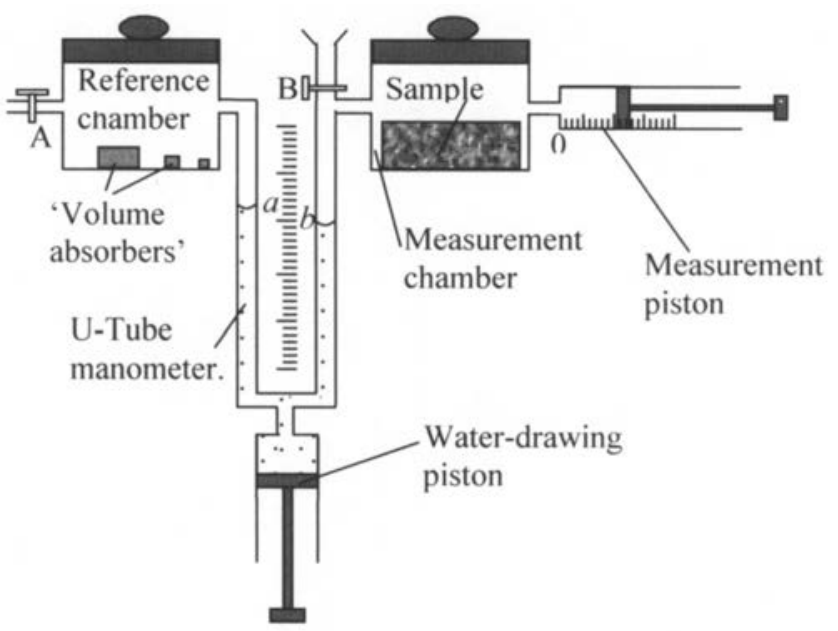

FIG. 2. Experimental setup for the measurement of porosity by comparison of air volumes. piston of $20 \mathrm{ml}$ capacity is connected to the measurement chamber. If smaller volumes are involved, a smaller piston of $10 \mathrm{ml}$ capacity can be used instead.

\section{B. Calibration}

A calibration experiment is carried out first in order to equalize the volumes of the reference chamber and the measurement chamber in the absence of sample and with the measurement piston to zero. The two chambers are first set at atmospheric pressure (valves A and B opened) and starting from a high level of water in both branches, A and B are closed and water is drawn. If the volumes of the two chambers were identical, the pressure difference $(a-b)$ would be close to zero. Equalizing the two volumes can be achieved by introducing volume absorbers, e.g., pieces of nonporous solid in the reference chamber and by repeating the procedure described in this section several times until $(a-b)$ approaches zero. The need to introduce volume absorbers in the reference chamber in order to equalize the volumes explains why, initially, the reference chamber must have a greater volume than that of the measurement chamber.

\section{Principle of a measurement with reduced thermal influence}

The proposed technique involves a number of operations that should be carried out in a certain order and is explained in this section. After the calibration has been completed, a porous sample is placed in the measurement chamber. This is done after the two chambers are set at atmospheric pressure (A and B opened). The reduction in the volume of air due to the introduction of the porous solid is compensated by varying the volume of the measurement piston (starting from the zero position). The measurement piston should be moved only when B is open. After each movement of the waterdrawing piston, the chambers are returned to atmospheric pressure by opening A and B. As water is drawn in the successive tries (with A and B closed), the difference in head levels $(a-b)$ between the two branches of the manometer approaches 0 when the volume in the measurement piston corresponds to the volume of solid of the porous sample. The proportion of solid (and hence the porosity) is obtained by dividing the volume of solid by the volume of the sample.

The originality of this method lies in the fact that the volumes of the two chambers are compared and equalized so that temperature variations or any atmospheric pressure fluctuation act simultaneously on both chambers. Consequently, the thermal effects nearly "cancel out" and this method has the advantage that the influence of temperature is considerably reduced. Also, the calibration experiment needs to be done only once, so that measurement on any new sample will involve only one measurement after placing the sample in the measurement chamber, thus minimizing the number of operations in the experimental procedure. Although minimized, the temperature still has an influence as the experimental system is not perfectly symmetrical. The movements of all the pistons involved in this experiment should be smooth and gentle. In particular, one should make sure that 
TABLE I. Porosity measurements results.

\begin{tabular}{lccc}
\hline \hline Sample Name & Information on sample & $\begin{array}{c}\text { Measured } \\
\text { porosity }\end{array}$ & $\begin{array}{c}\text { Reference } \\
\text { value }\end{array}$ \\
\hline $\begin{array}{l}\text { Spherical } \\
\text { particle }\end{array}$ & $\approx 1 \mathrm{~mm}$ particles with narrow size & $0.393 \pm 0.017$ & $0.36-0.45$ \\
$\begin{array}{l}\text { Redhill sand- } \\
\text { Grade } 14 / 25\end{array}$ & distribution & $0.448 \pm 0.019$ & $0.41 \pm 0.04$ \\
$\begin{array}{l}\text { Olivine sand } \\
\text { Expanded clay } \\
\text { granulates }\end{array}$ & Coarse sand $0.59 \pm 0.16 \mathrm{~mm}$ & $0.444 \pm 0.028$ & $0.425 \pm 0.024$ \\
$\begin{array}{l}\text { Laterlite LECA } \\
\text { Porous concrete } \\
\text { mix }\end{array}$ & $\begin{array}{c}\text { Fouble porosity sample (collection of } \\
\text { porous particles). } 2 \text { to 3 mm }\end{array}$ & $0.725 \pm 0.063$ & \\
$\begin{array}{l}\text { Sucrose } \\
\text { Cocrystalline } \\
\text { sugar }\end{array}$ & $\begin{array}{c}\text { RHP cement, Limestone dust, Sika } \\
\text { Plastocrete and water. }\end{array}$ & $0.312 \pm 0.021$ & \\
\hline \hline
\end{tabular}

tween the measurement piston and the chamber is slow. After some experience, it takes about $20 \mathrm{~min}$ to calibrate the device and about $15 \mathrm{~min}$ per sample to determining the porosity of materials described in the next section.

\section{MEASUREMENTS, RESULTS, AND PRECISION}

The porosities of seven samples were measured: two sands, expanded clay granulates, a porous concrete, spherical particles, and two sugar granulates. The results and useful information about the samples are listed in Table I. The porosities measured by the method proposed in this article were compared to reference values for three samples: the spherical particles and the two sands. It was not possible to compare the results with reference values for the expanded clay granulates, the porous concrete, or the sugar crystals.

\section{A. Spherical particles}

The particles studied were sugar beads with a particle size around $1 \mathrm{~mm}$ used to decorate cakes in bakeries. These beads represent an excellent model of uniform spherical particles with a very narrow particle size distribution. A sample volume of $28 \mathrm{ml}$ of beads was measured in a measuring cylinder. The error on the determination of the sample volume was taken to be $\pm 0.5 \mathrm{ml}$ ( $\pm 1.8 \%)$. The experiment was carried out and the final volume read on the large measurement piston was $17 \mathrm{ml}$ with an error estimated to $\pm 0.2 \mathrm{ml}$. Hence, the total error on the reading on the piston is estimated to be $\pm 0.4 \mathrm{ml}( \pm 2.4 \%)$ if the error in the calibration experiment is assumed to be the same. The overall precision is therefore close to $\pm 4.2 \%$ and the porosity is $1-17 / 28$ $=0.393 \pm 0.017$. The reference values displayed in Table I correspond to theoretical values for a random packing of spheres. The value of porosity generally accepted for a random dense packing of uniform spheres is 0.36 (Refs. 1 and 4). For a random loose packing of uniform spheres, the value of 0.45 can be taken as a reference. ${ }^{4}$ In the experiment, no particular action was taken (e.g., rolling, shaking, or compressing) to pack the sample. Apart from eventual electrostatic forces resulting from friction between particles, no interparticle interactions that can occur in water-saturated particles were expected and a measurement of porosity performed in air should give values between these two limits. The value of $0.393 \pm 0.017$ we obtained was in the expected range. The experiment was repeated several weeks later for this sample. The sample volume selected was the same as in the first experiment $(28 \mathrm{ml})$. In the second experiment, the calibration procedure was carried out first and the final value of the difference $(a-b)$ read was $+0.5 \mathrm{~mm}$. Then the sample was placed in the measurement chamber and the data recorded. Table II shows the sequence of data recorded in the measurement process. Starting from $18 \mathrm{ml}$, the volume set on the graduated piston was varied in successive tries: 18, 14, $17 \mathrm{ml}, \ldots$ and the corresponding values of $(a-b)$ were read: $+3.5,-3,+2 \mathrm{~mm}, \ldots$. This difference decreased until it reached a value close to the same difference of +0.5 $\mathrm{mm}$ obtained in the calibration process. The volume displayed on the piston was then considered to be the final value and the actual volume of solid. The value obtained for the

TABLE II. Example of recorded data for evaluation of porosity (data for the spherical particles).

\begin{tabular}{lcc}
\hline \hline $\begin{array}{c}\text { Volume set on measurement } \\
\text { piston in ml }\end{array}$ & $\begin{array}{c}\text { Pressure difference }(a-b) \\
(\mathrm{mm})\end{array}$ & $\begin{array}{c}\text { Approximate time before } \\
\text { taking the reading } \\
(\mathrm{min})\end{array}$ \\
\hline 18 & +3.5 & 1 \\
14 & -3 & 1 \\
17 & +2 & 1 \\
15 & -2.5 & 1 \\
15.7 & -1 & 2 \\
16 & -0.5 & 3 \\
16.4 (final value) & $\approx+0.5$ & 5 \\
\hline \hline
\end{tabular}


porosity was $0.414 \pm 0.017$. This greater value seems to indicate that the sample was less compacted than in the first experiment.

\section{B. Redhill and Olivine sands}

For the Redhill sand, a sample volume of $29 \pm 0.5 \mathrm{ml}$ (error $\pm 1.7 \%$ ) was selected. The porosity experiment was carried out and the final volume read on the large measurement piston was $16 \pm 0.4 \mathrm{ml}$ (error of $0.2 \mathrm{ml}$ for the measurement added to $0.2 \mathrm{ml}$ for the calibration, i.e., $\pm 2.5 \%$ ). The porosity was found to be $0.448 \pm 0.019$ (total error of $\pm 4.2 \%)$. The usual method by water saturation was used, providing a reference porosity of $0.41 \pm 0.06$. This value was obtained by pouring $22 \pm 0.5 \mathrm{ml}$ of sand in $34 \pm 0.5 \mathrm{ml}$ of water. The water level rose to a level of $47 \pm 0.5 \mathrm{ml}$ so that the volume of the solid was $13 \pm 1 \mathrm{ml}$. Although the total precision of $\pm 10 \%$ was not excellent, this measurement provided a reference value to which to compare the value obtained with the new method.

The same experiments (air-based method and water saturation) were performed for the Olivine sand. A sample volume of $13.5 \pm 0.5 \mathrm{ml}$ and a solid volume measured with the smaller piston of $7.5 \pm 0.2 \mathrm{ml}$ were measured. This error of $\pm 0.2 \mathrm{ml}$ corresponds to $\pm 0.1 \mathrm{ml}$ for the measurement added to $\pm 0.1 \mathrm{ml}$ for the calibration. For the water saturation experiment (sample volume of $40 \pm 0.5 \mathrm{ml}$, solid volume of $23 \pm 1 \mathrm{ml}$ ), the precision was slightly better than for the Redhill sand because it was possible to select a greater sample volume.

\section{Expanded clay granulates}

This material is composed of particles with a range of sizes between 2 and $3 \mathrm{~mm}$. The particularly of this material is that each particle itself is porous. The expected high value of porosity was confirmed by the experimental result. It may be noticed that this method leads to the measurement of the open porosity only. The trapped porosity corresponding to air inclusions inside the porous particles is not determined. There was no alternative method to which to compare the result as saturating the grains with water posed the problems of damage to the sample and modification of its porosities. Two main reasons explain why the precision was not as good as for the other samples. The greater size of the grains was responsible for a greater uncertainty in the evaluation of the sample volume (the value was $20 \pm 1 \mathrm{ml}$ ). The high porosity of the materials implied that the measured solid volume with the air-based system was small so that the relative error was greater. The reading on the small measurement piston was $5.5 \pm 0.2 \mathrm{ml}$ and the total error was $\pm 8.6 \%$.

\section{Porous concrete}

The sample volume was $24 \pm 1 \mathrm{ml}$ and the measured solid volume was $16.5 \pm 0.4 \mathrm{ml}$.

\section{E. Sugar crystals}

The porosities of an ordinary sugar and of a cocrystalline sugar were measured and compared. Cocrystalline sugar is

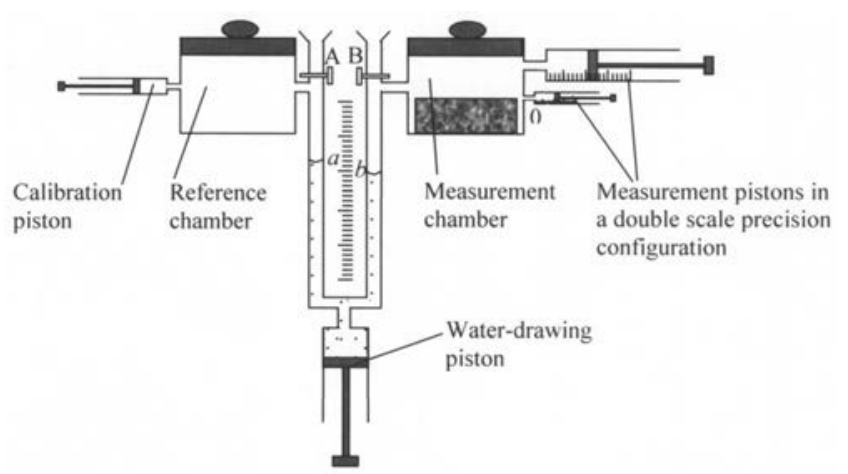

FIG. 3. Improvement in the design of the air volume comparison system for the measurement of porosity.

made up of spherical shaped agglomerates which incorporate some air. ${ }^{5}$ Because these agglomerates are porous, the bulk density of cocrystallized sugars $\left(0.62-0.64 \mathrm{~g} / \mathrm{cm}^{3}\right)$ is lower than that of conventional sugars $\left(0.81-0.84 \mathrm{~g} / \mathrm{cm}^{3}\right)$ (Ref. 6). The measured densities of the ordinary and the cocrystallized sugars in this study were, respectively, 0.95 and $0.61 \mathrm{~g} / \mathrm{cm}^{3}$. The porosities were measured and the expected higher value for the cocrystalline sugar was confirmed by the experimental results. A porosity of $0.377 \pm 0.014$ was obtained for ordinary sugar crystals while the porosity of cocrystalline sugar was found to be $0.583 \pm 0.029$ (see Table I).

\section{ALTERNATIVE DESIGN AND FUTURE IMPROVEMENTS}

Discarding the error on the measurement of the sample volume which does not depend on the proposed measurement system, the error on the reading of the volume of solid in the measurement chamber was in the order of $2.5 \%$ for the beads, the two sands, and the porous concrete. For the clay granulates this error was $3.6 \%$. This greater error can be explained by the fact that the clay granulates have a significantly higher porosity than the other materials resulting in a smaller volume of solid measured in the chamber. Since the sizes of the measurement chamber and of the porous samples are limited, improving the precision requires increasing the precision of the value read on the measurement piston as well as the precision of the calibration. A possible solution to achieve this is depicted in Fig. 3 where two measurement pistons are connected to the measurement chamber. This configuration corresponds to a double scale precision reading. The idea is that the larger piston provides a gross value of the volume while the smaller piston can be used for fine tuning. The capacity of the small piston should correspond to a convenient integer number of the unit graduation on the large piston, for example, $1 \mathrm{ml}$ capacity for $1 \mathrm{ml}$ unit graduation.

The improvement of the precision on the reading must be accompanied by an improvement in the calibration. A possible solution is to design the reference chamber slightly smaller that the measurement chamber and to connect a small piston to it. This solution avoids the repeated opening and closing of the reference chamber to introduce or remove the "volume absorbers." The equalization of the volumes is 
achieved by varying the volume of the calibration piston until $(a-b)$ is small. A greater flexibility as well as symmetry are gained with this modified system.

Although attractive, these solutions were not attempted in the present study. The reason for this is that the best solution to achieve excellent precision is to redesign the entire system in a similar way as Champoux et al. improved Beranek's design. The improvement of the present setup will require precise systems for varying the volumes (these improvements are more costly). A possible solution for this purpose is the use of precision motor driven syringe volume variators. A sensitive differential pressure piezometer will also be required as well as an improved thermal insulation for the chambers (the thermal effects are already greatly reduced in comparison to Beranek's method but can be reduced further). Because the implementation is far more expensive than the present device, it was not attempted in the present study. However, after these improvements are carried out, it is expected that our system will perform as well as the system of Champoux et al. but with less dependence upon temperature variations. Furthermore, this refined system can incorporate the new features described in Fig. 3, for even more flexibility and ease of use.

\section{DISCUSSION}

It is thought that the technique proposed in this article is the best possible to reduce the thermal effects on the measurements, the reason being that the volumes of the reference and measurement chambers are equal in the end so that the temperature variations (acting simultaneously on both chambers) "cancel out." If the proper modus operandi is followed, the measurement is fast, simple, and does not require the application of a complicated mathematical formula. The porosities of several materials were measured with a typical precision of the order 5\% for porosities of the order of 0.4 . It was also found that in the present experimental configuration, the error increases with porosity and the experimental setup presented in this article is adapted to the measurement of low porosities. More costly future improvements should increase the precision and permit the measurement of higher porosities for materials such as fibrous materials and highly porous foams with open cells (reticulated foams). The method yields the open porosity and this limitation must be borne in mind with respect to foams containing closed pores.

\section{ACKNOWLEDGMENT}

This work was supported by the Engineering and Physical Sciences Research Council (EPSRC) Grant No. GR/ R43761/01.

${ }^{1}$ T. Bourbié, O. Coussy, and B. Zinsner, Acoustics of Porous Media (Technip, Paris, 1987).

${ }^{2}$ L. L. Beranek, J. Acoust. Soc. Am. 13, 248 (1942).

${ }^{3}$ Y. Champoux, M. R. Stinson, and G. A. Daigle, J. Acoust. Soc. Am. 89, 910 (1991).

${ }^{4}$ G. Y. Onoda and E. G. Liniger, Phys. Rev. Lett. 64, 2727 (1990).

${ }^{5}$ A. C. Chen, Int. Sugar J. 96, 493 (1994).

${ }^{6}$ F. LaBell, Food Processing 52, 60 (1991). 